\title{
A STATISTICAL MODEL FOR DETERMINATION OF THE TYPE OF KNOWLEDGE MANAGEMENT APPROACH BASED ON ORGANIZATION PROCESSES
}

\begin{abstract}
Summary
Knowledge management is vital to organization management and is done by pursuing different strategies, which are mainly based on two basic knowledge management approaches called the explicit-oriented approach and the tacit-oriented approach. In this paper, we have tried to consider the type of knowledge strategy of organizations in a new classification including organizations with routine or non-routine processes. Thus, the two important knowledge strategies of organizations, the explicit-oriented and the tacit-oriented strategy, are evaluated using a questionnaire completed by 64 companies of either the type with routine or the type with non-routine processes. Then, the relation between the state of knowledge in the companies and the types of companies was determined by using logistic regression and it was found that the companies which use explicit knowledge operate more routinely and vice versa, the companies which use tacit knowledge operate less routinely.
\end{abstract}

Keywords: $\quad$ knowledge management strategy, tacit/explicit-oriented organization, routine/non-routine processes, logistic regression.

\section{Introduction}

Since the importance of knowledge as one of the most important resources of the organization is increasing, an organization in today's knowledge-oriented world should acquire a suitable strategy for creating value out of its intellectual property. In this area, different strategies are recommended [1]. It is broadly agreed that different organizations can choose from a variety of strategies for knowledge management based on their specific conditions and characteristics [1-3]. Perrow has classified organizations into organizations with routine processes (ORPs) and organizations with non-routine processes (ONPs) based on the number of exceptions encountered in their environment [4]. Lillrank has classified organization processes into three categories, standard, routine, and non-routine, based on their variability and uncertainty. Based on this, with the passage of time and an increase in organization knowledge, non-routine processes change into routine and standard processes $[5,6]$.

1.1 Knowledge management and its strategies

Company's knowledge management is a framework that considers business processes as the processes which create value added knowledge and empower knowledge management 
processes through changing and correcting processes, systems, and organizational culture with the help of knowledge tools and techniques [7]. Hamsen et al. have also defined two main strategies for knowledge management: the codification strategy and the personalization strategy [2]. In the codification strategy, the knowledge of the company is codified and stored in data banks and is accessible to everyone easily, while in the personalization strategy, knowledge is based on the person who has developed the knowledge and transfers it to others. In fact, the codification strategy is based on the people-to-document approach (explicit knowledge) while the personalization strategy is based on the people-to-people approach (tacit knowledge) [8]. Kim et al. have also considered four categories: outside codification, inside codification, outside personalization, and inside personalization, and their efficiency is totally dependent on contextual conditions of the company, such as the maturity of its information systems [9]. Shannak et al. have categorized knowledge-related approaches into three groups: the technology-oriented, the people-oriented, and the asset-oriented knowledge which is based on explicit knowledge, tacit knowledge, and knowledge economic value, respectively [7]. As the above mentioned studies show, the explicit-oriented and the tacitoriented approaches are presented as two main knowledge management approaches. Thus, we have considered these approaches in this paper.

Researchers believe that the organization will consider one of the knowledge management strategies as its main strategy and use other strategies as supporting strategies [2, 10]. There have been a large number of research efforts considering the choice of a suitable knowledge management strategy for companies and they show that choosing one main knowledge management strategy depends on different characteristics of a company. Linder et al. have studied the choice of a suitable knowledge management approach for temporary organizations which are usually project-oriented [11]. Hamsen et al. have stated that most of the mass production companies have the codification strategy and the companies with customized products and services are the companies that use personalized strategy [2]. Furthermore, Greiner et al. have suggested that the companies which need some improvement in their process efficiency should use the codification strategy and the companies aiming at extending their processes innovation should at first use the personalization strategy [12]. As the aforementioned studies show the most important approaches in the knowledge management area are the explicit-oriented and the tacit-oriented approach [10], and these two approaches will be discussed in this paper.

\subsection{Organizations with Non-routine Processes}

Perrow has classified organizations and their technologies based on exceptions and unexpected events happening in their environment and the extent to which these exceptions can be analyzed and a specific solution can be found. Perrow has called the companies with few exceptions ORPs. Mostly, companies with mass products or services that have identical and standard activities are of this type. In contrast, in ONPs, there are many exceptions that cannot be analyzed since pre-defined plans do not exist [4]. Moreover, Lillrank believes that organization processes are influenced by environmental changes and new needs. He categorizes organization processes based on their variability and uncertainty into three categories: standard, routine and non-routine processes. Lillrank believes that standard and routine processes are implemented permanently and repeatedly, and their input, process, and output are completely defined. On the other hand, he believes that non-routine processes are the processes that face an unknown input (a new need) and steps, and their output is completely vague [5]. Most of the organizations in the area of consultancy, healthcare, and project-oriented organizations have more non-routine processes compared to routine and standard processes $[5,6]$. 
Based on Organization Processes

In this paper, we aim to find which of the two most important strategies of knowledge management, the tacit-oriented or the explicit-oriented strategy, is more suitable for ONPs. In other words, ONPs choose a strategy for their knowledge management. The rest of this paper is organized as follows. In the next section, the research methodology is described. In section 3 , we present the results of an empirical study based on the proposed methodology. Finally, the concluding remarks are given in section 4 .

\section{Research methodology}

In this section we propose a new methodology to find the relation between knowledge management strategy and type of organization (ORP and ONP) using logistic regression. In the first subsection, the sampling method is presented.

\subsection{Sampling method}

The data of this experimental study was received through sampling in companies which are members of the Iranian Quality Management Association (IQMA) and participated in the Iranian National Quality Award (INQA). The companies have been chosen based on two criteria: 1- implementation of quality management system and/or 2- familiarity with the related concepts such as process management. In this study, the approach of key informants was used. Since business process excellence managers have an important role in defining and managing organization processes, they were asked to fill out the questionnaires. 120 excellence or quality assurance managers from the companies were invited to a technical meeting (seminar), which 90 of them attended.

After a detailed explanation of the questionnaire, 80 completed questionnaires were received and finally 64 of them were verified to be used in this study. Table 1 shows some simple statistics about the seminar participants who filled out their questionnaires completely and correctly.

Table 1 Seminar participant data

\begin{tabular}{|l|l|l|l|}
\hline \multicolumn{2}{|l|}{ Product or Service Type } & Organization Type \\
\hline Mass & 34 & Product & 34 \\
\hline Customized & 28 & Service & 28 \\
\hline Mass and Customized & 2 & Product or Service & 2 \\
\hline Number of Personnel & & Working Experience (years) & \\
\hline$<24$ & 6 & $<5$ & 10 \\
\hline $25-49$ & 8 & $6-10$ & 5 \\
\hline $50-99$ & 6 & $11-15$ & 13 \\
\hline $100-199$ & 4 & $16-20$ & 9 \\
\hline$>200$ & 40 & $>21$ & 27 \\
\hline
\end{tabular}

\subsection{Processes uncertainty}

Based on the definition of processes by Iillrank [5], a score sheet including three sections of Input $(I)$, Process $(P)$, and Output $(O)$ was designed with respect to the characteristics of each section. For instance, in the Input section, one of the characteristics is "The process inputs are completely clear and pre-defined". The representative of each company gives a score to each section between zero and 100. Finally, the value of process certainty $(C)$ is calculated by multiplying the scores of $I, P$ and $O$. Obviously, the smaller values of $C$ illustrate more uncertainty in the company processes. We need to mention that before using the score sheet in the seminar, the value of certainty for ten companies (from 
both manufacturing and service industries) was calculated based on the primary version of the score sheet. Then, the final version of the score sheet was designed according to the feedback received from the managers of those companies and three experts in the area of process management. The score sheet is given in Appendix 1.

\subsection{The method of classifying organizations}

At this stage, to divide the organizations into ORPs and ONPs, a meeting with 20 quality assurance managers of the participating companies (being in the manufacturing or service industry) was held. Based on the existing conditions of the organizations, organizational environment, types of their processes and the extent to which they face environmental changes, it was decided whether they are ORPs or ONPs. It is noteworthy that in this stage, we chose these companies based on their activities so that both ORPs and ONPs were included. For instance, it was predicted that the companies using mass production are more probable to be ORPs and the companies that provide customized services or organization in the healthcare area are more likely to be ONPs.

After that, a binary variable, namely $y$ was defined, where zero and one indicate an ORP and an ONP respectively. Since the variable $y$ depends on the variable $C$, the relation between these two variables was defined based on the logistic regression model. Then, the value and the probability of $y$ for the remaining 44 companies were obtained based on the value of their C. Hence the companies with a high probability for $y=0$ were defined as ONPs.

\subsection{Analysis of organization's knowledge approaches}

Standard and routine processes are replicable and pre-defined and are mostly implemented based on formal rules and documented procedures. Therefore, the management of such processes is system-oriented and their knowledge management approach is more likely to be explicit-oriented [13-16]. This is because non-routine processes are less predictable and documentable and their implementation is more based on the expertise and experience of people [17]. The knowledge management approach of this type of processes is more probably tacit-oriented $[13,14]$. Generally speaking, the more we move from nonroutine processes towards standard processes, the explicit knowledge level of the company increases $[13,18]$. As a result, in this study, the knowledge management approach (tacitoriented and explicit-oriented) is one of the differentiable specifications of ORPs and ONPs.

For determining the type and knowledge level of companies based on Yuvan, Nicolan et al., and Birasnav, a set of questions were defined [19-21]. For content validation, the questions were reviewed by six experts in meetings and the number of questions reduced to 13 divided in three sections, including knowledge acquisition (KA), knowledge application (KAP), and knowledge transfer (KT) (see Appendix 2). For each question, a five-point Likert scale ranging from 1 (totally disagree) to 5 (totally agree) was considered so that the higher number of points shows that the company's approach is more explicit-oriented. After receiving the completed questionnaires from 64 companies, Cronbach's Alpha was used to determine the reliability of the questionnaire for each of the three sections using the SPSS 21 software. The values of the indices are presented in Table 2.

Table 2 Values of Cronbach's alpha for knowledge management questionnaire

\begin{tabular}{|c|c|c|c|c|}
\hline Section & $\begin{array}{c}\text { Knowledge } \\
\text { acquisition }\end{array}$ & $\begin{array}{c}\text { Knowledge } \\
\text { application }\end{array}$ & $\begin{array}{c}\text { Knowledge } \\
\text { transfer }\end{array}$ & Total \\
\hline Cronbach's alpha & $\mathbf{0 . 8 1 0}$ & $\mathbf{0 . 7 9 4}$ & $\mathbf{0 . 7 6 2}$ & $\mathbf{0 . 8 2 9}$ \\
\hline
\end{tabular}

As Table 2 shows, the questionnaire has suitable reliability, because the value of Cronbach's alpha for each section is more than 0.7. Furthermore, the total Cronbach's alpha 
for the questionnaire is equal to 0.829 . This number indicates suitable reliability considering all questions together [20]. In addition, for measuring the validity, an exploratory factor analysis (EFA) was conducted by using the LISREL 8.8 software and the results are represented in Table 3. The results show that the analysis is appropriate since the value of the Kaiser-Meyer-Olkin (KMO) measure based on the principal component analysis (PCA) is greater than $0.6(0.77)$ and Bartlett's sphericity test is statistically significant at a level of less than 0.05 (0.00). In addition, the equamax rotation shows that almost all items have loading factors greater than 0.6. Moreover, the main indices of the EFA, consisting of Pvalue $=0.0183, \mathrm{RMSEA}=0.085, \mathrm{GFI}=0.84, \mathrm{CFI}=0.92, \mathrm{IFI}=0.92, \mathrm{NFI}=0.82$ and $\mathrm{NNFI}=0.89$ show the appropriateness of using this EFA [21].

Table 3 Exploratory factor analysis for knowledge management

\begin{tabular}{|c|c|c|c|}
\hline \multirow{2}{*}{ Indicators } & \multicolumn{3}{|c|}{ Latent factors } \\
\hline & KA & KAP & KT \\
\hline $\mathrm{x} 1$ & 0.700 & & \\
\hline x2 & 0.762 & & \\
\hline $\mathbf{x} 3$ & 0.555 & & \\
\hline$x 4$ & 0.718 & & \\
\hline $\mathbf{x} 5$ & 0.822 & & \\
\hline x6 & & 0.694 & \\
\hline $\mathbf{x} 7$ & & 0.763 & \\
\hline $\mathbf{x 8}$ & & 0.669 & \\
\hline x9 & & 0.622 & \\
\hline $\mathbf{x 1 0}$ & & 0.814 & \\
\hline $\mathbf{x 1 1}$ & & & 0.787 \\
\hline $\mathrm{x12}$ & & & 0.814 \\
\hline $\mathbf{x 1 3}$ & & & 0.840 \\
\hline Eigenvalue & 4.418 & 2.021 & 1.764 \\
\hline Explained variance & 33.986 & 15.547 & 13.567 \\
\hline Accumulated & 33.986 & 49.533 & 63.101 \\
\hline $\begin{array}{l}\text { Notes: Kaiser-Meyer-O } \\
\text { (KMO=0.726); Bartlett's } \\
p=0.002 ; \text { Extraction } \\
\text { (PCA); Rotation Meth } \\
\text { converged after five itera }\end{array}$ & $\begin{array}{l}\text { e of } \mathrm{Sa} \\
\text { st: } \chi^{2} \\
\text { acipal Co } \\
x \text { Rotatic }\end{array}$ & $\begin{array}{l}\text { pling A } \\
74.283 \text {, } \\
\text { aponent } \\
\text {; Rotat }\end{array}$ & $\begin{array}{l}\text { dequacy } \\
d f=51 \text {, } \\
\text { Analysis } \\
\text { ion has }\end{array}$ \\
\hline
\end{tabular}

\subsection{Model development}

In this step of examining the knowledge management approach of ONPs, a regression model between $y$ and the latent factors (KA, KAP and KT) coming from the exploratory factor analysis is determined. Thus, a link function will be created based on the factor scores and $y$. For more information about factor scores refer to Sharma [22]. Note that the link function between the factor scores and $y$ is defined as binary logistic regression. 


\section{The results of the empirical study}

In this section, based on our proposed methodology, a statistical analysis is conducted to determine the relation between the knowledge management factors (KA, KAP and KT) and the organization type (routine and non-routine processes). In the next subsection, the relation between $\mathrm{C}$ and probability of $y$ for 20 companies (that their types, $\mathrm{y}$, were known in advance) is determined.

\subsection{Classifying organizations}

In this subsection, the logistic regression model was applied to find the relation between $\mathrm{C}$ and probability of $y$ for 20 known companies as given in Equation 1. As mentioned before, $y$ is a binary variable, where zero indicates an ONP and one represents an ORP.

$$
\pi_{i}=\frac{e^{-1.253+0.066 c_{i}}}{1+e^{-1.253+0.066 c_{i}}}
$$

In Equation 1, $C_{i}$ is the value of certainty of the processes in the $i^{\text {th }}$ organization and $\pi_{i}$ is the probability of each treatment (or the probability of being an ORP). Moreover, values of the measures of association for the logistic regression model are given in Table 4.

Table 4 Association measurements of logistic regression model

\begin{tabular}{|c|c|}
\hline \multicolumn{2}{|c|}{ Index } \\
\hline Goodman-Kruskal Gamma & Somers'D \\
\hline $\mathbf{0 . 7 3}$ & $\mathbf{0 . 7 3}$ \\
\hline
\end{tabular}

Since the values of the measures of association are greater than 0.5 , the proposed model has an appropriate fitness value for predicting the type of ORPs and ONPs. As Equation 1 shows, the coefficient of $C_{i}$ is positive, meaning that, as $C_{i}$ increases, the probability of being an ORP increases as well. After deriving the logistic regression model, the probability of the response variable $(y)$ for the remained 44 companies was predicted by Equation 1, so that for the organizations with a probability greater than 0.5 , " $y=1$ " (i.e., these organizations are considered to be ORPs), and for organizations with a probability less than 0.5 , " $y=0$ " (i.e., these are considered to be ONPs). Therefore, the probability of the response variable was calculated for all 64 companies based on the values of process certainty of these organizations. Now, by knowing the value of the response variable (organization type) for all companies, we can find the relation between the response variable and the knowledge factor scores which will be discussed in the next subsection.

\subsection{Logistic regression model analysis and predicting probability of being an ORP}

As mentioned in the previous sections, a binary logistic regression model was used for determining a relation between the factor scores and the response variable. In this subsection, we firstly calculate the value of factor scores for the 64 organizations by using the Minitab 17.1 software and the results along with the type of the ORP and ONP are given in Table 5. 
Table 5 Factor scores and type of organization

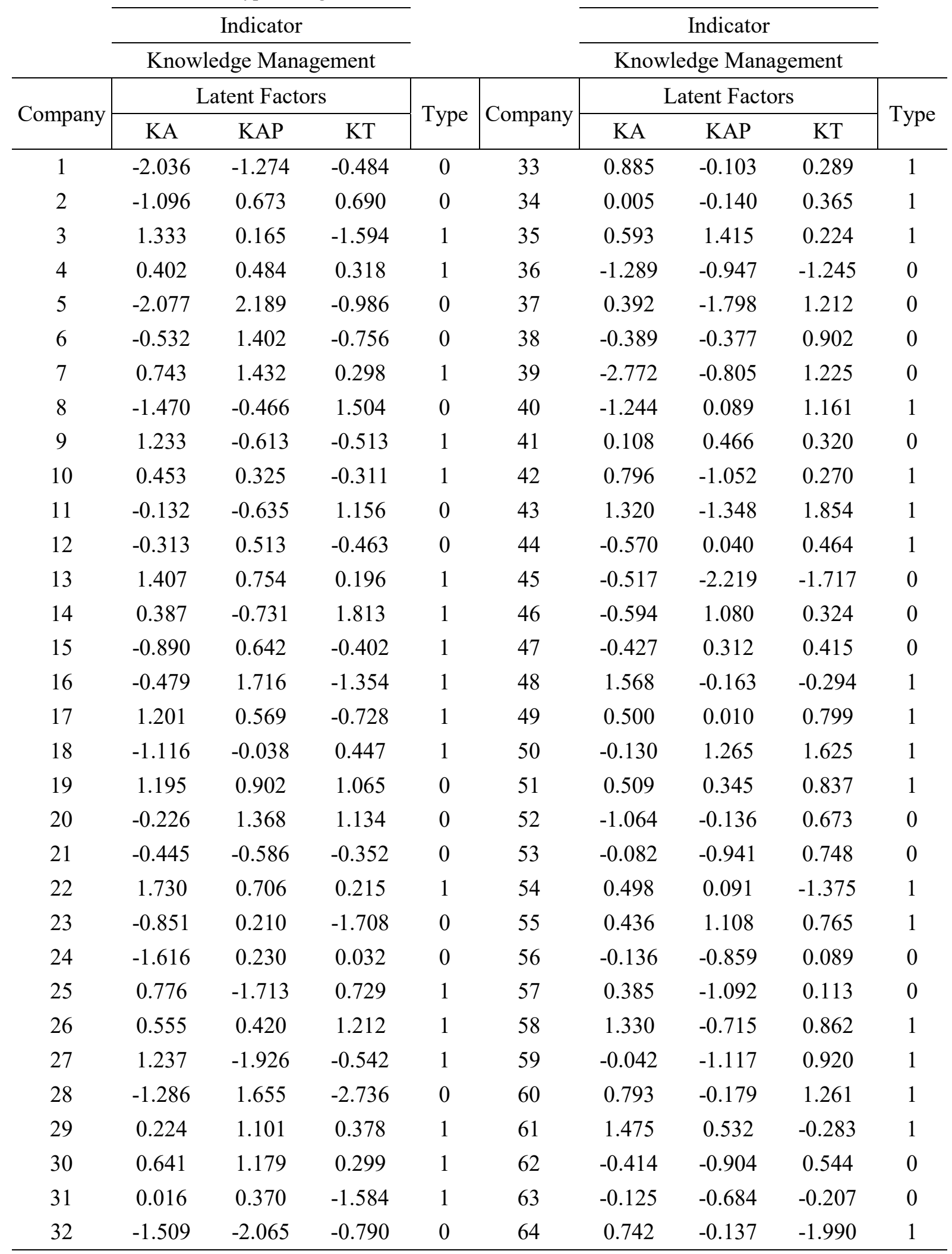

As Table 5 illustrates, out of the 64 organizations, 36 are ORPs and the rest of them are ONPs. Now, by using the scores of the knowledge management factors and the type of organization, a link function based on the binary logistic regression model can be determined. 
In order to derive the binary logistic regression model, the coefficients of three latent factors, i.e. KA, KAP, and KT, were estimated as given below.

$$
\widehat{\boldsymbol{\beta}}=\left[\begin{array}{llll}
0.323 & 2.102 & 0.582 & -0.141
\end{array}\right]
$$

Note that 0.323 is the constant parameter of the model and $2.102,0.582$ and -0.141 are the coefficients of KA, KAP and KT, respectively. On this basis, the binary logistic regression model was defined and for each organization the probability of being an ORP was calculated by using the Minitab 17.1 software. The probability of being an ORP for each organization is determined by Equation 2.

$$
\pi_{i}=\frac{e^{0.323+2.102 K A+0.582 K A P-0.141 K T}}{1+e^{0.323+2.102 K A+0.582 K A P-0.141 K T}}
$$
Table 6.

Values of the measures of association for the logistic regression model are given in

Table 6 Measures of association for logistic regression model

\begin{tabular}{|c|c|}
\hline \multicolumn{2}{|c|}{ Measurements } \\
\hline Goodman-Kruskal Gamma & Somers'D \\
\hline $\mathbf{0 . 7 7}$ & $\mathbf{0 . 7 7}$ \\
\hline
\end{tabular}

As Table 6 shows, the measures of association are greater than 0.5, meaning that the logistic regression model is appropriate. Therefore, the fitted model can be used for all the organizations to determine the probability of their routines to be based on their knowledge condition. The probability of being an ORP for each of the organizations, which is calculated based on 13 questions of the questionnaire, is given in Table 7. It is noteworthy that the variable $y$ in Table 7 is a non-metric response variable taking the values zero and one, where one indicates ORPs and zero represents ONPs.

\begin{tabular}{|c|c|c|c|c|c|c|c|c|c|c|c|c|c|c|c|}
\hline Organization & $\mathrm{x} 1$ & $\mathrm{x} 2$ & $\mathrm{x} 3$ & $\mathrm{x} 4$ & $\mathrm{x} 5$ & $\mathrm{x} 6$ & $\mathrm{x} 7$ & $\mathrm{x} 8$ & $\mathrm{x} 9$ & $\mathrm{x} 10$ & $\mathrm{x} 11$ & $\mathrm{x} 12$ & $\mathrm{x} 13$ & $y$ & Probability of being ORP \\
\hline 1 & 1 & 1 & 1 & 3 & 1 & 1 & 4 & 1 & 1 & 3 & 4 & 3 & 2 & 0 & 0.00965 \\
\hline 2 & 2 & 1 & 2 & 3 & 4 & 2 & 4 & 3 & 3 & 5 & 4 & 4 & 3 & 0 & 0.15627 \\
\hline 3 & 4 & 2 & 3 & 4 & 4 & 3 & 2 & 4 & 5 & 3 & 2 & 3 & 4 & 1 & 0.96912 \\
\hline 4 & 3 & 2 & 4 & 3 & 2 & 2 & 3 & 3 & 4 & 4 & 4 & 4 & 3 & 1 & 0.80318 \\
\hline 5 & 1 & 1 & 2 & 1 & 1 & 2 & 5 & 3 & 4 & 5 & 3 & 2 & 4 & 0 & 0.06739 \\
\hline : & $:$ & $:$ & $:$ & $\vdots$ & $\vdots$ & $:$ & $:$ & $:$ & $:$ & $\vdots$ & : & $:$ & : & : & $:$ \\
\hline 60 & 4 & 4 & 3 & 4 & 3 & 3 & 3 & 3 & 4 & 3 & 5 & 5 & 4 & 1 & 0.84650 \\
\hline 61 & 5 & 2 & 4 & 5 & 5 & 4 & 4 & 3 & 5 & 4 & 3 & 4 & 4 & 1 & 0.97756 \\
\hline 62 & 2 & 4 & 1 & 3 & 2 & 2 & 2 & 3 & 3 & 4 & 5 & 3 & 4 & 0 & 0.24031 \\
\hline 63 & 3 & 2 & 1 & 4 & 2 & 2 & 3 & 3 & 4 & 3 & 2 & 5 & 3 & 0 & 0.42342 \\
\hline 64 & 4 & 3 & 3 & 3 & 4 & 4 & 4 & 3 & 2 & 2 & 2 & 2 & 3 & 1 & 0.88933 \\
\hline
\end{tabular}

Table 7 Probability of being ORP for 64 organizations 
Based on Organization Processes

As it can be seen in Table 7, the probability of being an ORP for each organization based on the values of the 13 knowledge management variables is determined. Note that the scores of the latent factors are estimated based on the values of the 13 variables of knowledge management, and then Equation 2 is used to calculate the probability of being an ORP for each organization. Table 7 clearly reveals that the probability of being ORPs for ONPs such as $1,2,5$, etc. is low and this probability for ORPs like 3,4 , etc. is high. This indicates that the classification of the organizations is done correctly. But we must consider that the derived logistic regression model allows the prediction whether any other organizations are ORPs or ONPs based on their knowledge condition. For this purpose, different scenarios are simulated by using the MATLAB software as reported in Table 8 . In fact, by assigning random values to 13 variables (13 questions of the questionnaire) a number of simulated scenarios were generated. Then, the probability of being an ORP for each scenario was calculated by using the logistic regression model obtained earlier in this subsection.

Table 8 Different scenarios to predict organization type

\begin{tabular}{|l|l|l|l|l|l|l|l|l|l|l|l|l|l|c|}
\hline Scenario & $\mathrm{x} 1$ & $\mathrm{x} 2$ & $\mathrm{x} 3$ & $\mathrm{x} 4$ & $\mathrm{x} 5$ & $\mathrm{x} 6$ & $\mathrm{x} 7$ & $\mathrm{x} 8$ & $\mathrm{x} 9$ & $\mathrm{x} 10$ & $\mathrm{x} 11$ & $\mathrm{x} 12$ & $\mathrm{x} 13$ & Probability of being ORP \\
\hline 1 & 4 & 1 & 2 & 2 & 1 & 1 & 3 & 2 & 2 & 4 & 4 & 2 & 1 & 0.8205 \\
\hline 2 & 2 & 3 & 1 & 4 & 3 & 1 & 1 & 1 & 1 & 3 & 5 & 4 & 3 & 0.6431 \\
\hline 3 & 1 & 4 & 3 & 2 & 3 & 3 & 2 & 4 & 3 & 4 & 4 & 4 & 3 & 0.9164 \\
\hline 4 & 2 & 1 & 1 & 1 & 4 & 3 & 4 & 2 & 1 & 3 & 2 & 5 & 5 & 0.6348 \\
\hline 5 & 2 & 2 & 1 & 2 & 1 & 3 & 2 & 2 & 3 & 1 & 3 & 4 & 2 & 0.1791 \\
\hline 6 & 2 & 1 & 3 & 4 & 4 & 1 & 1 & 3 & 2 & 5 & 5 & 5 & 2 & 0.9172 \\
\hline 7 & 1 & 2 & 2 & 1 & 3 & 2 & 1 & 3 & 2 & 2 & 3 & 3 & 3 & 0.4046 \\
\hline 8 & 1 & 2 & 2 & 2 & 2 & 3 & 1 & 1 & 3 & 3 & 4 & 2 & 5 & 0.5771 \\
\hline 9 & 1 & 1 & 1 & 2 & 1 & 5 & 2 & 5 & 1 & 2 & 2 & 2 & 4 & 0.0569 \\
\hline 10 & 2 & 1 & 1 & 1 & 2 & 5 & 4 & 5 & 1 & 1 & 5 & 3 & 4 & 0.2873 \\
\hline
\end{tabular}

It can be seen that the ten scenarios are classified into two different types. Note that since the probability of being ORPs for the scenarios $5,7,9$, and 10 is less than 0.5 , these organizations are ONPs. Because the probability of being ORPs for the remained scenarios is greater than 0.5 these organizations are ORPs. But in this paper it is claimed that by an increase in the values of the 13 variables of knowledge management, the organization moves toward being an ORP. In other words, when the values of knowledge management variables of an organization increase, the probability of being an ORP for that organization grows up. Thus, we performed a sensitivity analysis to evaluate the impact of these variables on the probability of being an ORP. For this reason, the effect of the variables on the probability of being routine was calculated, and a part of this analysis is presented in Table 9. It is noteworthy that the first scenario in Table 8 is used as the reference scenario for the sensitivity analysis. 
Table 9 Evaluating sensitivity of being an ORP to variables

\begin{tabular}{|c|c|c|c|c|c|c|c|c|c|c|c|c|c|c|}
\hline Scenario & $\mathrm{x} 1$ & $\mathrm{x} 2$ & $\mathrm{x} 3$ & $\mathrm{x} 4$ & $x 5$ & $x 6$ & $\mathrm{x} 7$ & $\mathrm{x} 8$ & x9 & $\mathrm{x} 10$ & $\mathrm{x} 11$ & $\mathrm{x} 12$ & $\mathrm{x} 13$ & $\begin{array}{c}\text { Probability } \\
\text { of being } \\
\text { ORP }\end{array}$ \\
\hline Reference & 4 & 1 & 2 & 2 & 1 & 1 & 3 & 2 & 2 & 4 & 4 & 2 & 1 & 0.8205 \\
\hline 1 & 2 & 1 & 2 & 2 & 1 & 1 & 3 & 2 & 2 & 4 & 4 & 2 & 1 & 0.5964 \\
\hline 2 & 5 & 1 & 2 & 2 & 1 & 1 & 3 & 2 & 2 & 4 & 4 & 2 & 1 & 0.8469 \\
\hline 3 & 4 & 3 & 2 & 2 & 1 & 1 & 3 & 2 & 2 & 4 & 4 & 2 & 1 & 0.9493 \\
\hline 4 & 4 & 1 & 1 & 2 & 1 & 1 & 3 & 2 & 2 & 4 & 4 & 2 & 1 & 0.5985 \\
\hline 5 & 1 & 4 & 4 & 2 & 1 & 1 & 3 & 2 & 2 & 4 & 4 & 2 & 1 & 0.9779 \\
\hline 6 & 4 & 1 & 2 & 1 & 1 & 1 & 3 & 2 & 2 & 4 & 4 & 2 & 1 & 0.7757 \\
\hline 7 & 4 & 1 & 2 & 4 & 1 & 1 & 3 & 2 & 2 & 4 & 4 & 2 & 1 & 0.8732 \\
\hline 8 & 4 & 1 & 2 & 2 & 3 & 1 & 3 & 2 & 2 & 4 & 4 & 2 & 1 & 0.9203 \\
\hline 9 & 4 & 1 & 2 & 2 & 1 & 2 & 3 & 2 & 2 & 4 & 4 & 2 & 1 & 0.9015 \\
\hline 10 & 4 & 1 & 2 & 2 & 1 & 1 & 1 & 2 & 2 & 4 & 4 & 2 & 1 & 0.7277 \\
\hline 11 & 4 & 1 & 2 & 2 & 1 & 1 & 5 & 2 & 2 & 4 & 4 & 2 & 1 & 0.8693 \\
\hline 12 & 4 & 1 & 2 & 2 & 1 & 1 & 3 & 1 & 2 & 4 & 4 & 2 & 1 & 0.8218 \\
\hline 13 & 4 & 1 & 2 & 2 & 1 & 1 & 3 & 4 & 2 & 4 & 4 & 2 & 1 & 0.8726 \\
\hline 14 & 4 & 1 & 2 & 2 & 1 & 1 & 3 & 2 & 1 & 4 & 4 & 2 & 1 & 0.8017 \\
\hline 15 & 4 & 1 & 2 & 2 & 1 & 1 & 3 & 2 & 3 & 4 & 4 & 2 & 1 & 0.8439 \\
\hline 16 & 4 & 1 & 2 & 2 & 1 & 1 & 3 & 2 & 2 & 2 & 4 & 2 & 1 & 0.4810 \\
\hline 17 & 4 & 1 & 2 & 2 & 1 & 1 & 3 & 2 & 2 & 5 & 4 & 2 & 1 & 0.8977 \\
\hline 18 & 4 & 1 & 2 & 2 & 1 & 1 & 3 & 2 & 2 & 4 & 1 & 2 & 1 & 0.5896 \\
\hline 19 & 4 & 1 & 2 & 2 & 1 & 1 & 3 & 2 & 2 & 4 & 5 & 2 & 1 & 0.8638 \\
\hline 20 & 4 & 1 & 2 & 2 & 1 & 1 & 3 & 2 & 2 & 4 & 4 & 1 & 1 & 0.8168 \\
\hline 21 & 4 & 1 & 2 & 2 & 1 & 1 & 3 & 2 & 2 & 4 & 4 & 3 & 1 & 0.8492 \\
\hline 22 & 4 & 1 & 2 & 2 & 1 & 1 & 3 & 2 & 2 & 4 & 4 & 2 & 2 & 0.8475 \\
\hline
\end{tabular}

Table 9 shows that if the value of each of the 13 variables of knowledge management increases, the probability of being an ORP also increases. As an example, by changing the value of variable $\mathrm{x} 1$ from 4 to 2 , the probability decreases from 0.8205 to 0.5964 and if $\mathrm{x} 1$ increases from 4 to 5 , the probability increases from 0.8205 to 0.8469 .

\section{Conclusion}

This study proposes a model which helps managers to make the right decision about their knowledge management strategy in such a way that the value of the 13 variables for their organization is identified, the type of organization (ORP or ONP) is determined and then based on the organization type, the KM strategy (tacit-oriented or explicit-oriented) is determined. The results confirm that as the 13 variables of knowledge management become closer to 5, the probability of being an ORP increases and also as the variables get closer to 1 , 
then the probability of being an ORP decreases, i.e., the probability of being an ONP grows. Note that the questionnaire was designed in such a way that high values of these variables mean that the organizational knowledge is more of the explicit-oriented type while low values of the variables indicate that the organizational knowledge is more of the tacit-oriented type. Hence, our claim that the probability of being an ORP increases as the values of each of the 13 variables of knowledge management increase, is substantiated. We can conclude that the results of this study confirm that as the level of the explicit-oriented knowledge in an organization increases, the organization moves toward being an ORP and also as the level of the tacit-oriented knowledge in an organization increases, the organization moves toward being an ONP.

But as it was mentioned earlier, the researchers believe that the organizations can choose one of the knowledge management strategies as the main one and use the others as complementary to or for supporting the main strategy. Hence, it is clear that ONPs, which, based on the results of this study, mainly use the tacit-oriented strategy, can also consider the explicit-oriented approach as a supporting strategy to their main strategy.

\section{REFERENCES}

[1] Haggie, K. and J. Kingston, Choosing your knowledge management strategy. Journal of Knowledge Management Practice, 2003. 4(4).

[2] Hansen, M.T., N. Nohria, and T. Tierney, What's your strategy for managing knowledge? The Knowledge Management Yearbook, 1999. p. 2000-2001.

[3] Kamara, J.M., C.J. Anumba, and P.M. Carrillo, A CLEVER approach to selecting a knowledge management strategy. International journal of project management, 2002. 20(3): p. 205-211. DOI: 10.1016/S0263-7863(01)00070-9

[4] Perrow, C., A framework for the comparative analysis of organizations. American sociological review, 1967: p. 194-208. DOI: 10.2307/2091811

[5] Lillrank, P., The quality of standard, routine and nonroutine processes. Organization Studies, 2003. 24(2): p. 215-233. DOI: 10.1177/0170840603024002344

[6] Lillrank, P. and M. Liukko, Standard, routine and non-routine processes in health care. International Journal of Health Care Quality Assurance, 2004. 17(1): p. 39-46. DOI: 10.1108/09526860410515927

[7] Shannak, R.O., M. Ra'ed, and M. Ali, Knowledge management strategy building: Literature review. European Scientific Journal, 2012. 8(15).

[8] Jordan, J. and P. Jones, Assessing your company's knowledge management style. Long range planning, 1997. 30(3): p. 322-398. DOI: 10.1016/S0024-6301(97)00019-8

[9] Kim, T.H., et al., Understanding the effect of knowledge management strategies on knowledge management performance: A contingency perspective. Information \& management, 2014. 51(4): p. 398416. DOI: $10.1016 /$ j.im.2014.03.001

[10] Li, Y., et al. The Complementary Effect of Knowledge Management Strategies on Firm Performance. in Proceedings of the 21st International Conference on Industrial Engineering and Engineering Management 2014. 2015. Springer. DOI: 10.2991/978-94-6239-102-4_132

[11] Lindner, F. and A. Wald, Success factors of knowledge management in temporary organizations. International journal of project management, 2011. 29(7): p. 877-888. DOI: $10.1016 /$ j.ijproman.2010.09.003

[12] Greiner, M.E., T. Böhmann, and H. Krcmar, A strategy for knowledge management. Journal of knowledge management, 2007. 11(6): p. 3-15. DOI: 10.1108/13673270710832127

[13] Schafermeyer, M., D. Grgecic, and C. Rosenkranz. Factors influencing business process standardization: A multiple case study. in System Sciences (HICSS), 2010 43rd Hawaii International Conference on. 2010. IEEE. 
[14] Choi, B. and H. Lee, An empirical investigation of KM styles and their effect on corporate performance. Information \& management, 2003. 40(5): p. 403-417. DOI: 10.1016/S0378-7206(02)00060-5

[15] G. Dukić, G. Kozina, M. Milković, Assessment of the knowledge management project at Croatian polytechnics. Tehnički vjesnik, Vol. 22 No. 2 , 2015. DOI: 10.17559/TV-20140326034118

[16] D. Pamučar, P. Atanasković, M. Miličić, Modeling of fuzzy logic system for investment management in the railway infrastructure. Tehnički vjesnik, Vol. 22 No. 5 , 2015. DOI: 10.17559/TV-20140626104653

[17] Lillrank, P., The quality of standard, routine and nonroutine processes. Organization Studies, 2003. 24(2): p. 215-233. DOI: 10.1177/0170840603024002344

[18] Davenport, T.H. and L. Prusak, Working knowledge: How organizations manage what they know1998: Harvard Business Press.

[19] López-Nicolás, C and Á.L. Meroño-Cerdán, Strategic knowledge management, innovation and performance. International journal of information management, 2011. 31(6): p. 502-509. DOI: $10.1016 /$ j.ijinfomgt.2011.02.003

[20] Huang, Y.-H., Measuring Individual and Organizational Knowledge Activities in Academic Libraries with Multilevel Analysis. The Journal of Academic Librarianship, 2014. 40(5): p. 436-446. DOI: $10.1016 /$ j.acalib.2014.06.010

[21] Birasnav, M., Knowledge management and organizational performance in the service industry: The role of transformational leadership beyond the effects of transactional leadership. Journal of Business Research, 2014. 67 (8): p. 1622-1629. DOI: 10.1016/j.jbusres.2013.09.006

[22] Sharma, S. "Applied Multivariate Techniques". University of South Carolina, (1996).

Submitted: $\quad 03.11 .2015$

Accepted: $\quad 20.9 .2016$
Farnoosh Bagheri

Rassoul Noorossana

Industrial Engineering Department of Iran

University of Science and Technology,

Tehran, Iran. 
A Statistical Model for Determination of the Type of Knowledge Management Approach

Based on Organization Processes

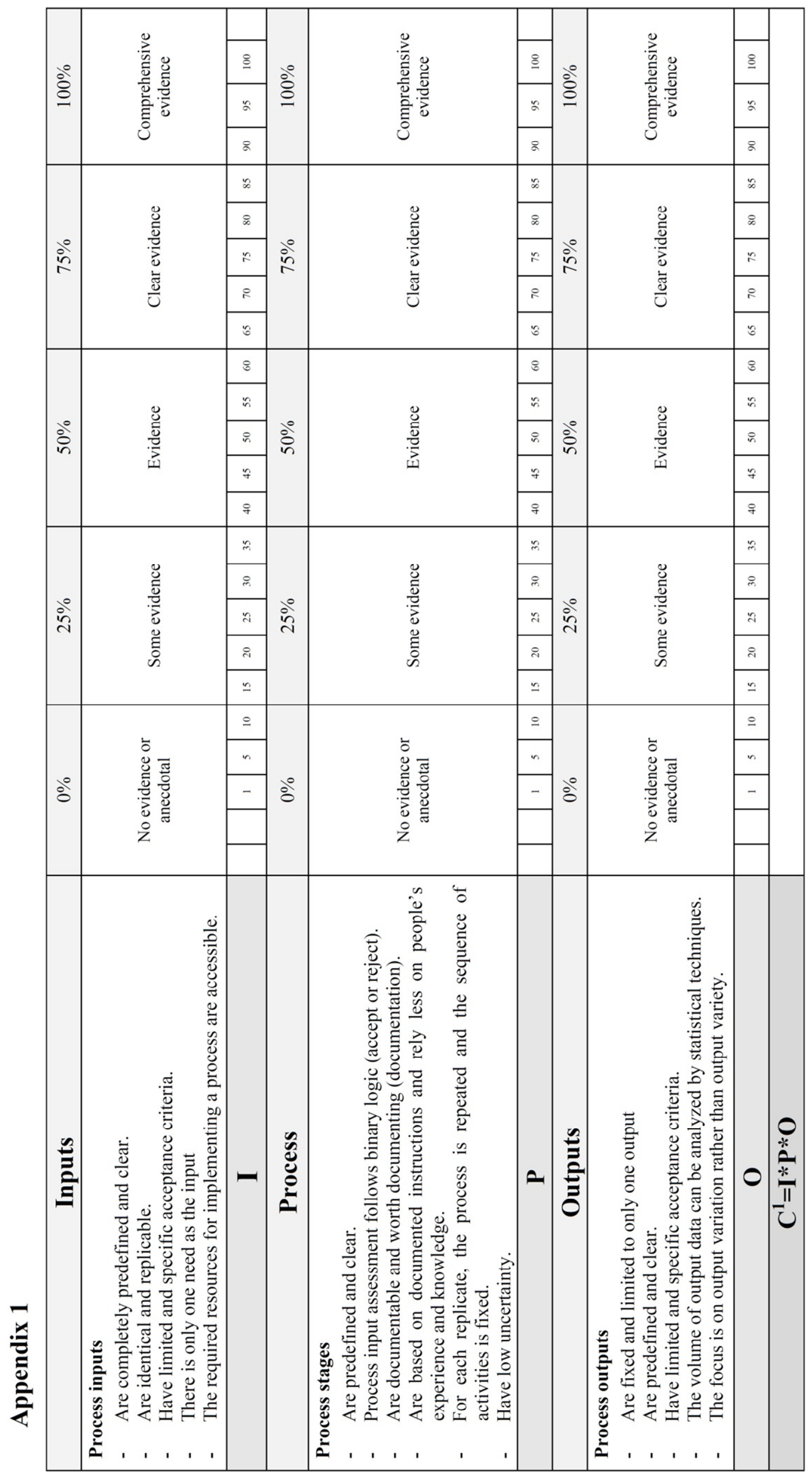




\begin{tabular}{|c|c|c|c|c|c|c|c|c|c|c|c|c|c|}
\hline$\dddot{\underline{u}}$ & $\overline{\bar{d}}$ & $\bar{\Xi}$ & $\overline{\bar{d}}$ & $\Xi$ & ¿ָ & $\Xi$ & $\bar{\Xi}$ & ¿্ & $\bar{\beth}$ & 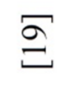 & $\overline{\mathrm{d}} \overline{\mathrm{d}}$ & פ & 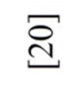 \\
\hline 递 & \multicolumn{5}{|c|}{ Knowledge Acquisition } & \multicolumn{5}{|c|}{ Knowledge Applicant } & \multicolumn{3}{|c|}{$\begin{array}{l}\text { Knowledge } \\
\text { Transfer }\end{array}$} \\
\hline 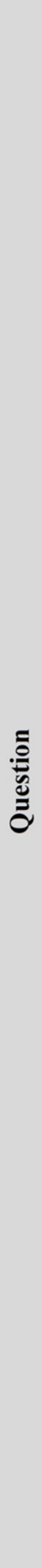 & 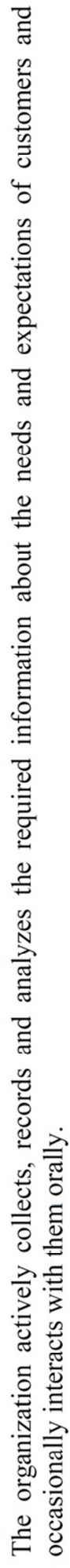 & 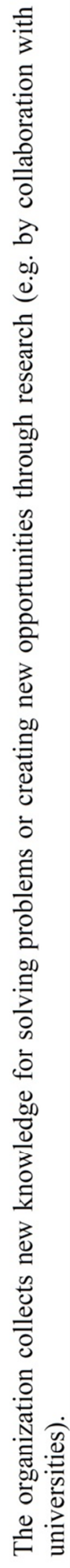 & 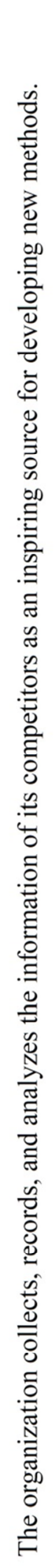 & 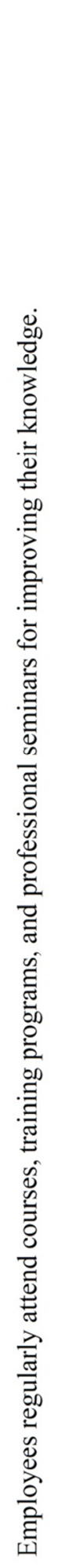 & 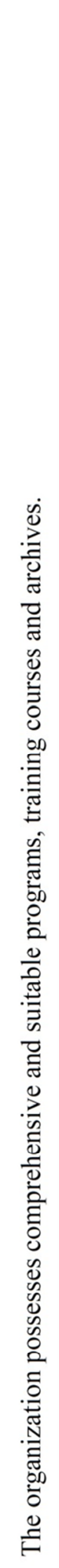 & 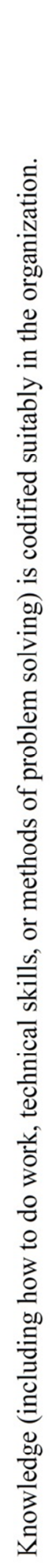 & 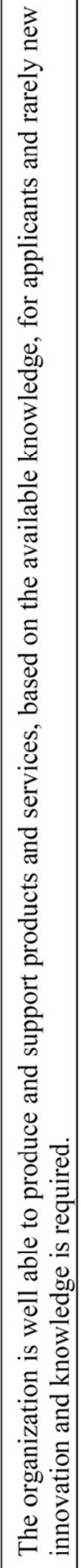 & 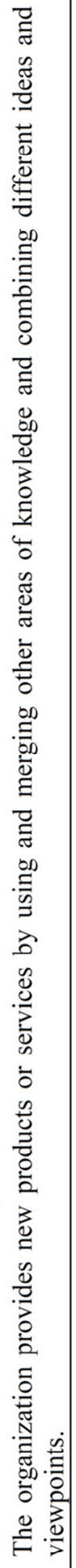 & 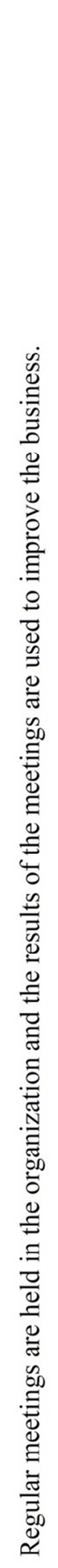 & 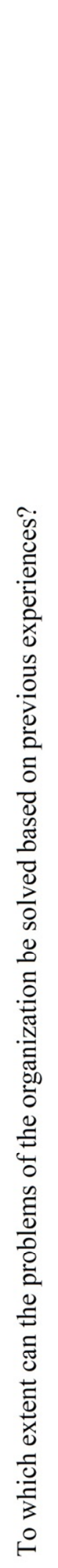 & 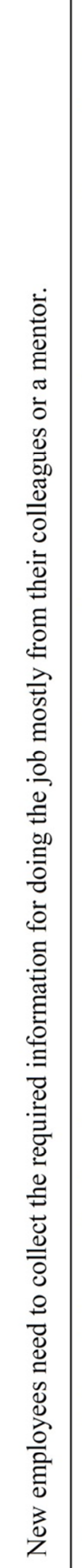 & 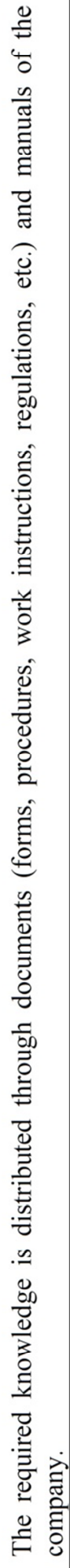 & 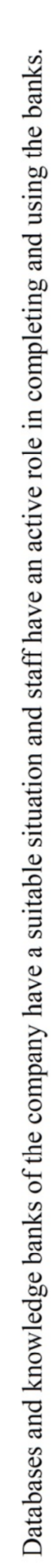 \\
\hline ż & - & $N$ & $m$ & $\nabla$ & in & 0 & $r$ & $\infty$ & $a$ & $\stackrel{0}{ }$ & $=$ & $\simeq$ & -1 \\
\hline
\end{tabular}

